\title{
NON-PUERPERAL UTERINE INVERSION: A CASE REPORT
}

\author{
C. O. FOFIE ${ }^{1}$ and P. BAFFOE ${ }^{2}$ \\ ${ }^{1}$ Upper West Regional Hospital - Obstetrics and Gynaecology, $P$ O Box 6, Wa, Ghana \\ ${ }^{2}$ Bolgatanga Regional Hospital, Department of Obstetrics and Gynaecology, P.O. Box 26, Bolgatanga, Ghana
}

Corresponding Author: Dr Chris Opoku Fofie

Conflict of Interest: None declared

\section{SUMMARY}

Non-puerperal uterine inversion is rare. A 42-year old woman presented with lower abdominal pain, offensive vaginal discharge and a huge protruding mass per vaginum. A clinical diagnosis of non-puerperal uterine inversion was made and she successfully underwent vaginal hysterectomy. A high index of suspicion is required to make a prompt diagnosis.

\section{INTRODUCTION}

Non-puerperal uterine inversion has been described as a rare occurrence by several authors but how really rare is it has not been defined ${ }^{(1-8)}$. However, the fact that many gynaecologists might not see any in their entire practice gives a clue as to its infrequent nature.

We describe here a 42-year old woman who was diagnosed with non-puerperal uterine inversion and successfully underwent vaginal hysterectomy in the Upper West Regional Hospital in Ghana.

\section{CASE REPORT}

A 42 year- old woman with four successful vaginal deliveries, last delivery five years ago and all children alive, was referred from a District Hospital as a case of cervical cancer for further management.

Prior to the referral, she had a two-year history of irregular menstrual flow and intermittent lower abdominal pain which got worse four days before her admission. She also noted a very offensive vaginal discharge and a protruding mass in her vulva three days before referral.

On examination, she was well-nourished, well hydrated and pale. No significant findings on other systems. On vaginal examination, a large offensive necrotic mass attached to a smooth surfaced globular mass was seen.(see Figure 1) Cervical os could not be identified. On rectal examination, uterus could not be felt; rather a vacuum was felt anteriorly. Haemoglobin level was $5.5 \mathrm{~g} / \mathrm{dl}$ so two units of cross-matched blood was transfused.

\section{Email:fofiy2000@yahoo.com}

On pelvic ultrasound examination, uterus could not be identified. That increased the suspicion of uterine inversion. Patient consented for hysterectomy and was prepared accordingly with intravenous fluids and antibiotics

Under spinal anaesthesia, patient was cleaned and draped in lithotomy position. A transverse incision was made at the cervico-uterine junction, dissecting anteriorly till bladder was separated and the anterior peritoneum was opened. (see Figure 2) A full thickness longitudinal incision was made from the level of the cervix to the fundus of the uterus, exposing this way both fallopian tubes, ovaries and round ligaments.(see Figure 3)

These structures were clamped transected and ligated bilaterally. The cardinal ligament, uterosacral ligament and uterine arteries were separately clamped, transected and ligated; permiting uterus to be extirpated.

The peritoneum was closed and vaginal cuff transfixed to uterosacral and cardinal ligaments.

Postoperative period was uneventful and patient was discharged on the sixth day. Subsequent review visits at four weeks; client had recovered fully and was ready to continue her normal business.

\section{DISCUSSION}

Non-puerperal uterine inversion is usually precipitated by tumours sited at the fundus of the uterus which exert traction force to cause the inversion, although some cases have been reported with no association with tumours.

The major factors that contribute to its occurrence are: tumour attachment site, thickness of the tumour pedicle, tumour size, thin uterine wall and dilatation of the cervix. ${ }^{5}$ Mwinyoglee et al in their review report that $97.4 \%$ were associated with tumours, out of which $20 \%$ were malignant. $^{6}$ 
Takano et al on the other hand report $92 \%$ association with tumours out of which $63 / 88$ (71.6\%) were leiomyomas and equally $20 \%$ malignant tumors. ${ }^{7}$

The need to conduct histopathology studies on all samples cannot be over emphasised.

Based on the degree of inversion, genital inversion can be classified in to partial and total, though some authors have outlined four distinct stages. ${ }^{8}$

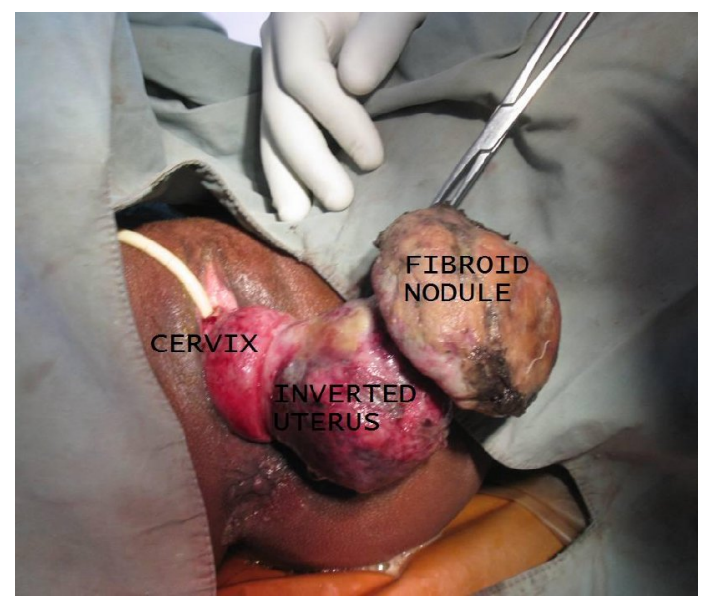

Figure 1 Complete inversion of the uterus and the fibroid nodule through the cervix.

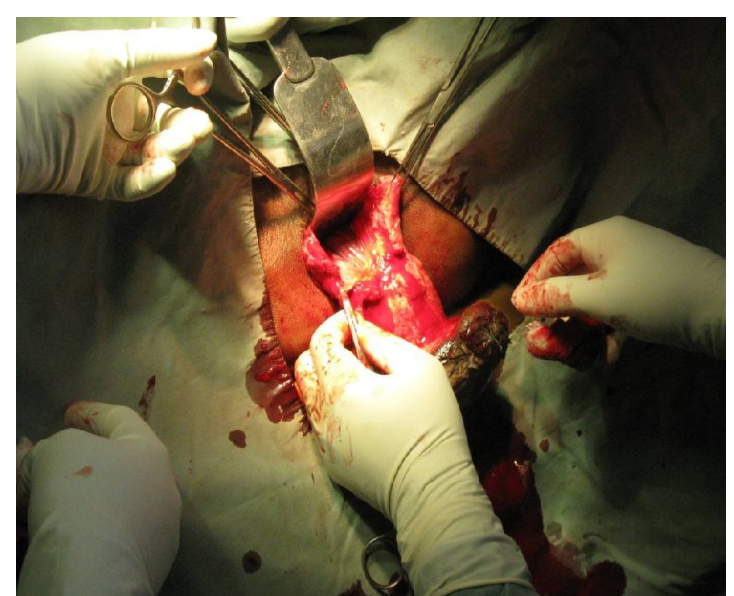

Figure 2 Aperture of the anterior peritoneum

Non-puerperal uterine inversion can also be classified into acute and chronic based on the onset and evolution. The acute is more dramatic and characterised by severe pain and haemorrhage whereas the chronic is insidious and characterised by pelvic discomfort, vaginal discharge, irregular vaginal bleeding and anaemia. ${ }^{9,10}$

The diagnosis is said to be difficult and requires high index of suspicion especially when the inversion is partial. $^{7,11}$
Lewin et al. recommend the use of T2-weighted MRI scans to detect a U-shaped uterine cavity, thickened and inverted uterine fundus on a sagittal image and a 'bulls-eye' configuration on an axial image as indicative signs of uterine inversion. ${ }^{12}$ This however, is not readily available in most hospital settings in developing countries.

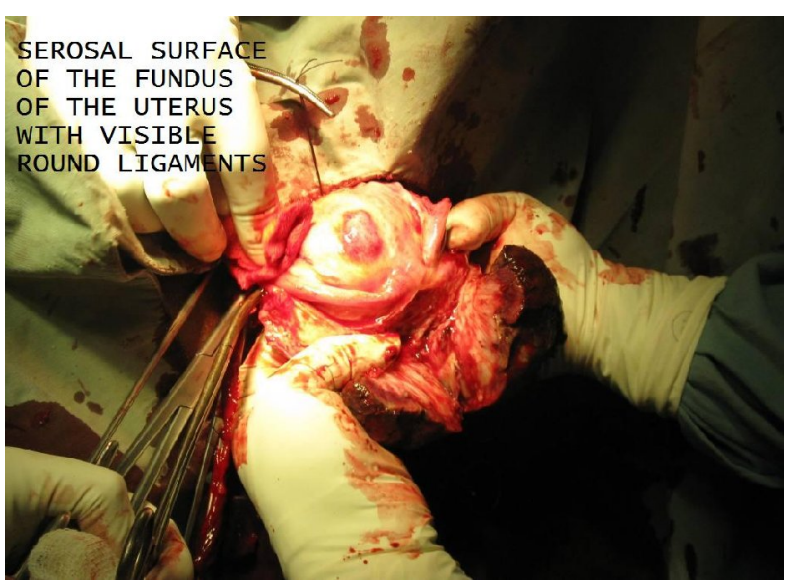

Figure 1 Transection of the uterus exposing the serosal surface of the uterine fundus and fallopian tubes.

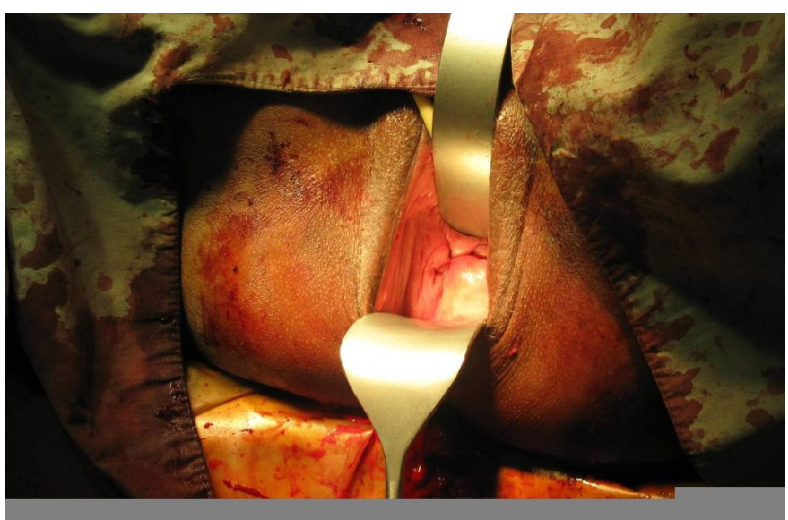

Figure 2 Final image after vaginal hysterectomy.

Reposition procedures like that of Johnson are more likely to be successful in acute inversion but in chronic cases, surgery is imperative. Depending on the clients reproductive desire and associated conditions, surgical reposition or hysterectomy could be considered. Spinell and Kustner are similar trans-vaginal surgical reposition techniques with the basic differences being that Spinell's approach is anterior and requires dissection of the bladder and has uterine incision on anterior wall while Kustner's is posterior approach with incision on the posterior uterine wall ${ }^{4}$, which makes it a bit easier and safer. 
Most surgeons use the abdominal route for hysterectomy. With some basic skills of the reposition techniques, vaginal hysterectomy could be carried out briskly and safely. In the case we present, the objective was to perform a vaginal hysterectomy with Spinell's technique as a guiding principle. After dissecting the bladder away and opening the peritoneum, a longitudinal incision towards the fundus was made like Spinell's, then the infundibulopelvic ligaments were clamped as suggested by Kopal to prevent massive trombo-embolic phenomenon. ${ }^{11}$ The rest was the standard vaginal hysterectomy procedure.

Though non-puerperal uterine inversion is uncommon, the few cases will still have to be managed without prior experience. High index of suspicion for the diagnosis and clear knowledge about gynaecological surgery will permit a successful outcome.

\section{REFERENCES}

1. Rosales Aujang E, Gonzales Romo R. Nonpuerperal uterine inversion. Gynecol obstet Mex. 2005; 73: 328-331

2. Lai FM, Tseng P. Non-puerperal uterine inversion: a case report. Singapore Med J 1993; 34: 466-468.

3. Eigbefoh JO, Okogbenin SA, Omorogbe F, Mabayoje PS. Chronic uterine inversion secondary to submucous fibroid: a case report. Niger J Clin Pract 2009 Mar; 12 (1):106-7
4 Safdarian L, Aleyassin A, Forootan M, KamalianN , Ahmadzadeh A.Non puerperal uterine inversion: a case report. Acta Medica Iranica 2003; 41(1): 59-61.

5. Lascarides E, Cohen M. Surgical management of non-puerperal inversion of the uterus. Obstet Gynecol 1968;32:376-81.

6. Mwinyoglee J, Simelela N, Marivate M. Non puerperal uterine inversions: a two-case report and review of the literature. Central African $\mathrm{J} \mathrm{Med}$ 1997;43:268

7. Takano K, Ichikawa $\mathrm{Y}$, Tsunoda $\mathrm{H}$, et al. Uterine inversion caused by uterine sarcoma: a case report. Jpn Clin Oncol 2001; 31(1): 39-42

8. Skinner GN, Louden KA. Nonpuerperal uterine inversion associated with an atypical leiomyoma. Aust N Z J Obstet Gynaecol. 2001; 4:100 - 101.

9. Krenning RA, Dorr PJ, De Groot WH et al. Nonpuerperal uterine inversion. Case report. $\mathrm{Br} J$ Obstet Gynaecol 1982;89:247-9.

10. Gowri V.Uterine inversion and corpus malignancies.A historical review. Obset Gynecol Surv 2000; 55: 703-707.

11. Kopal S, Seckin NC, Turhan NO. Acute uterine inversion due to a growing submucous myoma in an elderly woman: case report. Eur J Obstet Gynecol Reprod Biol. 2001; 99:118 - 120.

12. Lewin JS, Bryan PJ. MR imaging of uterine inversion. J Comput Assist Tomogr 1989;13:3579 